\title{
Effects of $N$-Benzylpyrazinium Hexafluoroantimonate Concentration on Rheological Properties in Cationic Epoxy Cure System
}

\author{
Youn Cheol Kim, Soo-Jin PARK, and Jae-Rock LeE ${ }^{\dagger}$ \\ Advanced Materials Div., Korea Research Institute of Chemical Technology, \\ P.O. Box 107, Yusong, Taejon 305-600, Korea
}

(Received March 17, 1997)

\begin{abstract}
The rheological properties and initiation mechanism during the reactions of new catalytic $(N$-benzylpyrazinium hexafluoroantimonate, BPH) epoxy thermosetting system with increase of BPH concentration have been studied by Fourier transform infrared spectroscopy (FT-IR), differential scanning calorimetry (DSC), and steady shear measurements. This cationic catalyst system turned out to have an availability as thermal latent initiator in the epoxy curing reaction. The dependence of viscosity on processing variables could be explained by structural change owing to the composition dependence of initiation reactions with increasing of BPH concentration. The temperature dependence on the induction time is well described by the Arrhenius expression, and the activation energies $\left(E_{t}\right)$ have similar values for various compositions, which indicates that the overall curing mechanisms are nearly same.
\end{abstract}

KEY WORDS Cationic Cure / Thermally Latent Initiator / Rheological Properties /

Epoxy resins are generally used in advanced composites as matrices due to their excellent mechanical and thermal properties. However there are some problems such as toxicity of amine and the deterioration of electrical properties at high temperature and humidity, and inherently brittle behavior in the case of epoxy/amine system as it is widely used in various fields. On the other hand, the cationic epoxy formulations have long term stability at room temperature, and cure rapidly when exposed to high temperature. Particularly, the cationic epoxy system could improve the deterioration of electrical properties which is leaded to the hydrophilic character of the amine functional group in epoxy/amine system. Focused on long term stability and electrical properties, an increasing aspect has been studied on the cationic epoxy curing. ${ }^{1-4}$ Crivello $^{1}$ and Abu-Abdoun ${ }^{2}$ reported that the triarylsulfonium salts and benzyl phosphonium salts can serve as photo-induced cationic initiators in the polymerization of epoxy resins. And it has been proved by Pappers et al. ${ }^{3}$ and Endo et al. ${ }^{4}$ that several sulfonium salts act as thermally latent cationic initiator in the curing reaction of epoxy resins, cyclic ethers, and vinyl monomers. Gu et al. ${ }^{5}$ and Morio et $a l^{6}{ }^{6}$ also reported that the aliphatic sulfonium salts can be also excellent thermally latent initiators for epoxy resins without any co-initiator. Generally, the network formation leading to the crosslinking in polymers is known as a complex process and it is of a specific interest in both basic and applied studies. As the reaction proceeds, the thermosetting polymer undergoes the immense changes in rheological properties resulting in a rapid increase in the molecular weight. At the gel point, there is an irreversible process from a viscous liquid to an elastic, insoluble network. Gelation does not inhibit the reaction. Nevertheless, from the processing point of view, it is a critical since the polymer no longer flows after gel point. Hence, one of the most important factors influencing the process of thermosetting resins is a viscosity control. Knowledge of structure-viscosity relations

\footnotetext{
† To whom all correspondence should be addressed.
}

can be useful in obtaining the optimum parameters for reactive processing operation, in providing a general understanding of the network formation mechanism, and in determining the final properties. In most curing systems, the reaction takes place at different kinetic stages, first slowly indicated linear growth and then quickly indicated well developed three-dimensional network. Gelation takes place through the two step process, associated with a dramatic increase of viscosity. Although there has been considerable interest in rheological behavior and structural change for epoxy/amine system, ${ }^{7-11}$ little progress has been made in elucidating the rheology-structure relationships for epoxy/catalyst system. Lee et al. ${ }^{12}$ developed a new class of Lewis acid catalysts, 1,2-substituted-1,1-dimethylhydrazinium hexafluoroantimonates, and found that these salts serve as thermally latent cationic initiator in the curing and polymerization of glycidyl phenyl ether.

The purpose of this paper, thus, is to synthesize new $\mathrm{N}$-benzylpyrazinium hexafluoroantimonate catalysts with $N$-benzyl group containing pyridium salt and to obtain a detailed and precise information concerning the reaction mechanism and variable dependence of rheological properties using FT-IR, DSC, and steady shear measurements.

\section{EXPERIMENTAL}

\section{Materials}

Epoxy resin used in this study was diglycidylether of bisphenol A (DGEBA, YD 128 supplied from Kukdo Chem. Co. of Korea). Epoxide equivalent weight of the DGEBA was $185-190 \mathrm{~g} / \mathrm{eq}$. and the density was 1.16 $\mathrm{g} \mathrm{cm}^{-3}$ at $25^{\circ} \mathrm{C}$.

Synthesis of Catalyst. To $250 \mathrm{ml}$ flask equipped with mechanical stirrer was added $1.60 \mathrm{~g}(20 \mathrm{mmol})$ of pyrazine and $7.30 \mathrm{~g}(42.7 \mathrm{mmol})$ of benzyl bromide. The mixture was reacted in room temperature for 24 hours. The collected white precipitate of benzylpyrazinium bromide salt by filtration is dissolved in $30 \mathrm{ml}$ distilled water. Next, $5.17 \mathrm{~g}(20 \mathrm{mmol})$ of $\mathrm{NaSbF}_{6}$ was added and the white 


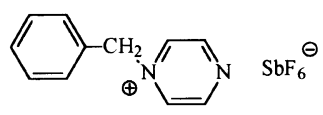

Chemical Structure of BPH

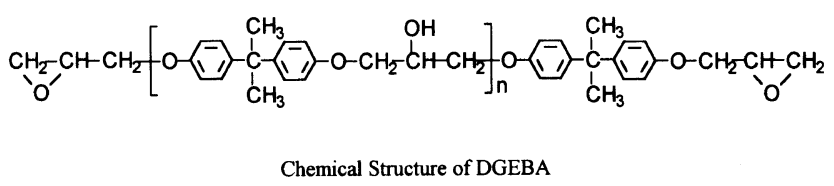

Figure 1. The chemical structure of the DGEBA and BPH.

product that was formed was filtered. And recrystallization from methanol made $4.84 \mathrm{~g}(59.5 \%)$ of pure white $\mathrm{N}$-benzylpyrazinium hexafluoroantimonate (BPH). From DSC thermogram, the endothermic peak temperature was $140.1^{\circ} \mathrm{C}$.

The purity and the chemical structures of product were confirmed by the elemental analysis, FT-IR, and the ${ }^{1} \mathrm{H}$ NMR as follows.

For FT-IR (KBr); 1514, 1358, 1223, 1073, 1015, 767, $726,662 \mathrm{~cm}^{-1}$.

For ${ }^{1} \mathrm{H}$ NMR (acetone- $d_{6}$ in ppm from tetramethylsilane)

Peaks for pyridine ring $(9.33-9.38,9.65-9.70 \mathrm{ppm})$

Peaks for aromatic ring $(7.70-7.47 \mathrm{ppm})$

Peaks for $-\mathrm{CH}_{2}-(6.18 \mathrm{ppm})$.

For elemental analysis

Calculated for $\mathrm{C}_{11} \mathrm{H}_{11} \mathrm{~N}_{2} \mathrm{SbF}_{6}$ :

$\mathrm{C}, 32.45 \% ; \mathrm{H}, 2.70 \%$; N $6.88 \%$.

Found for $\mathrm{C}_{11} \mathrm{H}_{11} \mathrm{~N}_{2} \mathrm{SbF}_{6}$ :

$\mathrm{C}, 32.90 \% ; \mathrm{H}, 2.74 \% ; \mathrm{N}, 6.91 \%$.

DGEBA and BPH structures are shown in Figure 1.

\section{Sample Preparation}

The required amount of catalyst (BPH) was accurately weighted into a $250 \mathrm{ml}$ beaker equipped mechanical stirrer and was dissolved in acetone. And then the moderate amount of epoxy (DGEBA) added. The beaker containing the sample was stirred for $10 \mathrm{~min}$ and degassed for $60 \mathrm{~min}$ before measuring. The catalyst concentrations for the used composition correspond to epoxy/ $\mathrm{BPH}$ ratios of $99.5: 0.5,97: 3$, and $95: 5$.

In order to analyze DSC results after thermal treatment, the environmental chamber of rheometer is filled with liquid nitrogen, rapidly quenching the sample and thus stopping the reaction at a specific point during cure. The temperature in the chamber dropped below $100^{\circ} \mathrm{C}$ from $150^{\circ} \mathrm{C}$ in less than $30 \mathrm{~s}$. The gelled sample is then removed from the parallel plates and analyzed by DSC.

\section{Measurements}

DSC measurements were carried out with Du Pont DSC 910 supported by a Du Pont thermal analyzer. The amount of sample was about $10-15 \mathrm{mg}$. The heating rate used was $10^{\circ} \mathrm{C} \mathrm{min}^{-1}$. And the scanning range was from 50 to $350^{\circ} \mathrm{C}$.

The FT-IR instrument used was a Hartmann \& Brawn Model Bomen MB 102 Spectrophotometer. The scans were from 400 to $4000 \mathrm{~cm}^{-1}$ and required $40 \mathrm{~s}$ to complete. Since the scans were conducted at high tem-

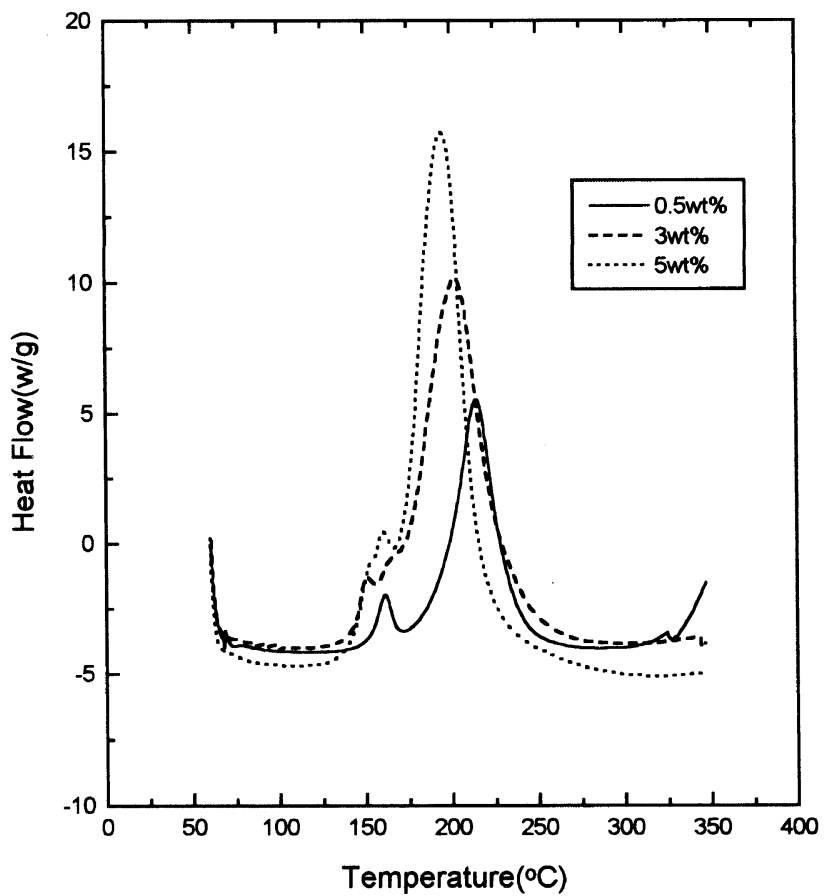

Figure 2. DSC thermogram of the untreated sample (heating rate is $\left.10^{\circ} \mathrm{C} \min ^{-1}\right)$.

peratures, a Grasedy-Specac Hot Cell was used to mount the samples. A Grasedy-Specac Temperature Controller (Model Eurotherm) was used along with heating elements and a thermocouple to control the temperature of the hot cell. Maximum 20 scans per run were carried out.

The steady shear viscosities at isothermal conditions were monitored using the parallel plate geometry on Physica (Rheo Lab. MC10). The $50 \mathrm{~mm}$ disposable plates were pre-heated in the rheometer environmental chamber for approximately $10 \mathrm{~min}$ at setting temperature before test. The gap between the plates was $0.5 \mathrm{~mm}$. After loading the sample, the temperature of the chamber was equilibrated to setting temperature in less than a minute. The temperature range was from 120 to $200^{\circ} \mathrm{C}$. The range of shear rate was from 0.5 to $20 \mathrm{~s}^{-1}$ in order to avoid network breakdown and slippage.

\section{RESULTS AND DISCUSSION}

\section{Thermal Behavior and FT-IR Measurements}

Figure 2 shows dynamic DSC thermograms for the epoxy resins containing $0.5,3$, and $5 \mathrm{wt} \%$ of BPH. From the multimodal exothermic peaks of DSC thermogram, these systems usually undergo more than one type of reaction and BPH can be excellent thermally latent initiator for epoxy resins without any co-initiator. These results show the similar behavior with that reported ${ }^{5,6}$ for epoxy-cured system by aliphatic sulfonium salts. In general, the polymerization reaction of cationic epoxy system leads to a Lewis acid process. ${ }^{13} \mathrm{Gu}$ et al. ${ }^{5}$ who had studied on diphenyliodonium hexafluoroarsenate/ epoxy system suggested that the two different curing reactions occur. Based on Gu's suggestion and DSC results, it may be considered that two separate initiation reactions behave as follows; 

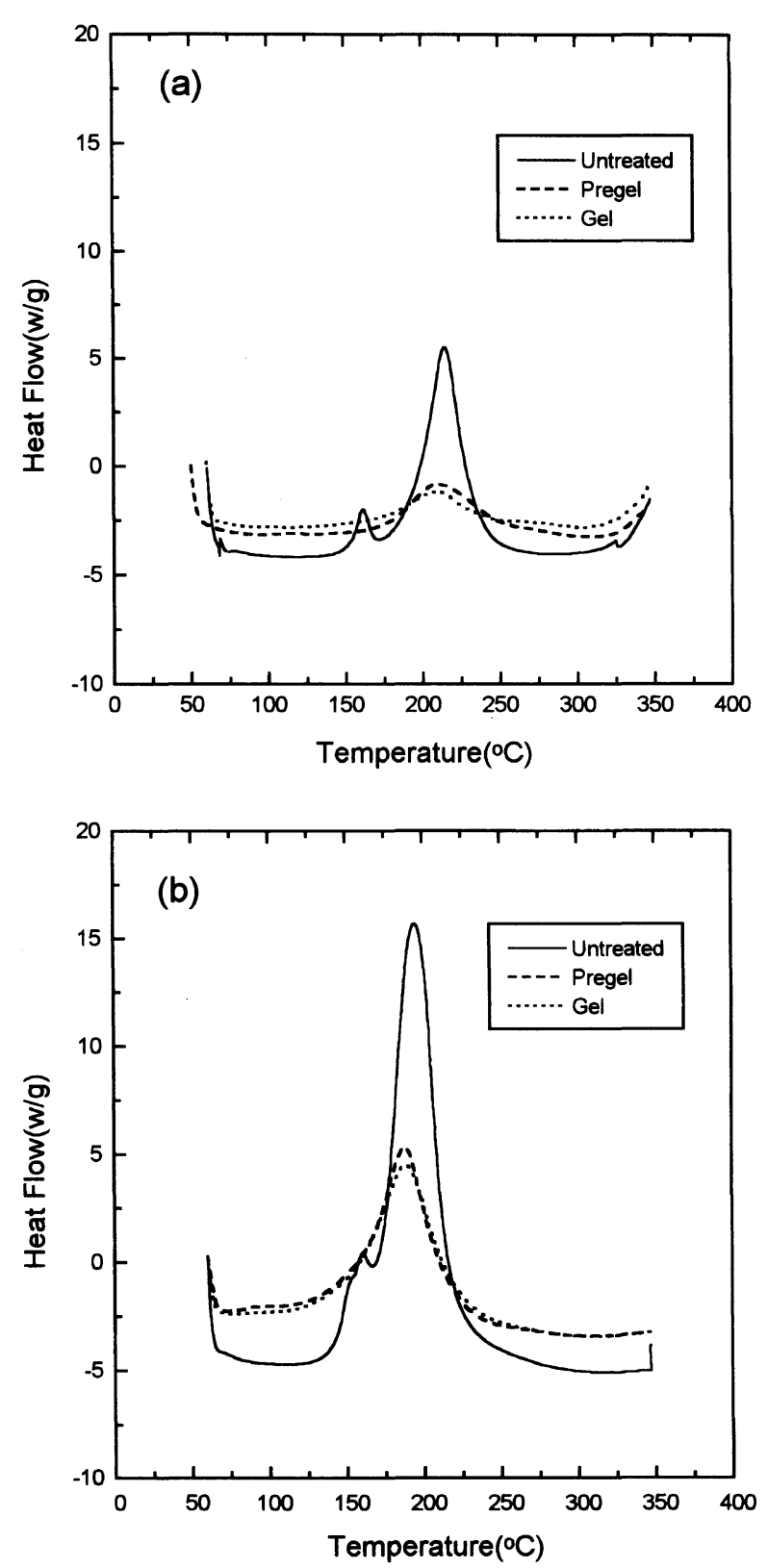

Figure 3. DSC thermogram of the thermal treated sample (heating rate is $10^{\circ} \mathrm{Cmin}^{-1}$ ): (a) $0.5 \mathrm{wt} \%$; (b) $5.0 \mathrm{wt} \%$.

$$
\begin{aligned}
& \mathrm{BPH}+\text { Epoxide } \underset{\Delta}{\longrightarrow} \\
& \mathrm{Ph}-\mathrm{CH}_{2}-\left(\mathrm{O}^{+} \text {of Epoxide }\right)-\mathrm{SbF}_{6}^{-}+\mathrm{Ph}-\mathrm{N}_{2} \\
& \mathrm{BPH}+\mathrm{R}-\mathrm{OH} \underset{\Delta}{\longrightarrow} \\
& \mathrm{Ph}-\mathrm{CH}_{2}-\mathrm{OR}+\mathrm{Ph}-\mathrm{N}_{2}+\mathrm{H}^{+} \mathrm{SbF}_{6}^{-}
\end{aligned}
$$

(where $\mathrm{R}-\mathrm{OH}$ represents hydroxyl groups in the epoxy resins)

The formation of $\mathrm{H}^{+} \mathrm{SbF}_{6}^{-}$in the reaction (b) starts the ring opening polymerization by Lewis acid process. The presence of two small exothermic peaks in Figure 2 indicates the existence of two separate initiation processes which differ in reactivity, and the separate behavior is enlarged by DSC thermograms of 1 and $2 \mathrm{wt} \%$ even though it is not present here. These two small peaks may be the evidence of the reaction between epoxides and BPH, and the reaction between epoxides and hydroxyl

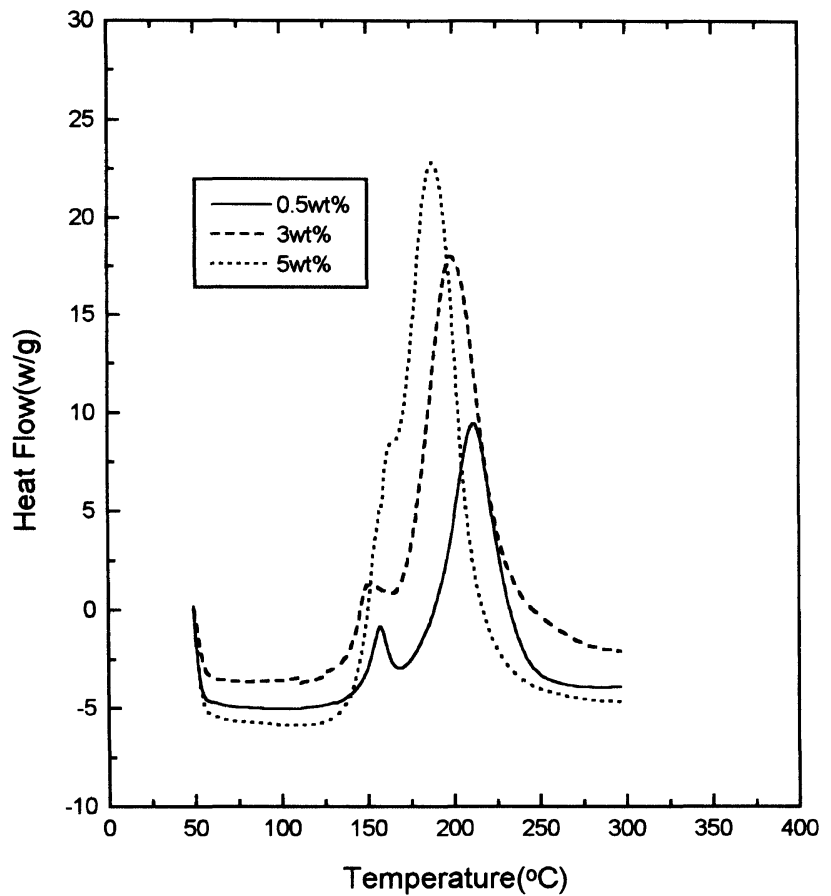

Figure 4. DSC thermogram of epoxy resin containing no hydroxyl group (heating rate is $10^{\circ} \mathrm{C} \mathrm{min}^{-1}$ ).

groups in epoxy chains. These reactions rapidly behave in catalytic process, as the results of disappearing two exothermic peaks for treated samples, as shown in Figure 3. Compared with DSC results of the higher concentration samples, the thermogram of $0.5 \mathrm{wt} \%$ of $\mathrm{BPH}$ shows single peak in the low temperature exothermic region. One explanation for this observation may be that the reaction between epoxides and hydroxyl groups in epoxy resins is negligible because of small amount of $\mathrm{BPH}$. From these results, it seems a reasonable conclusion that the gelation begins with the initiation reaction between epoxides and $\mathrm{BPH}$ or between hydroxyl groups in the epoxy resins and $\mathrm{BPH}$. As the concentration of $\mathrm{BPH}$ increases, the availability of the radical to react with the epoxides in the initial stage of cure would be more as a result of which the main peak temperature is shifted to a lower value. The total heat of polymerization also increases with increasing the concentration of $\mathrm{BPH}$, which is due to occurrence of more crosslinking. In order to analyze the low temperature exothermic region from further investigation, DSC thermograms of the treated samples by viscometer at $150^{\circ} \mathrm{C}$ were compared with untreated sample, as shown in Figure 3. Pregel denotes the quenched sample when the viscosity starts increasing, and gel means the quenched sample when the value of viscosity reaches to $30 \mathrm{~Pa} \mathrm{~s}^{-1}$. All thermograms of treated samples showed single peak. These results may be explained by the fact that the initiation reaction almost finishes at the initial stage of gelation. In order to simplify the curing reaction studies, DSC measurements for an epoxy system containing no hydroxyl group performed under the same test procedures. Epoxy resin used in this study was diglycidylether of bisphenol $F$ (DGEBF, YDF 161 from Kukdo Chem. Co of Korea). As expected from proposed reaction mechanism, DSC thermograms show single peak in low temperature exothermic region even though the concentration of $\mathrm{BPH}$ 
Table I. The thermal characteristic of DGEBA/BPH system

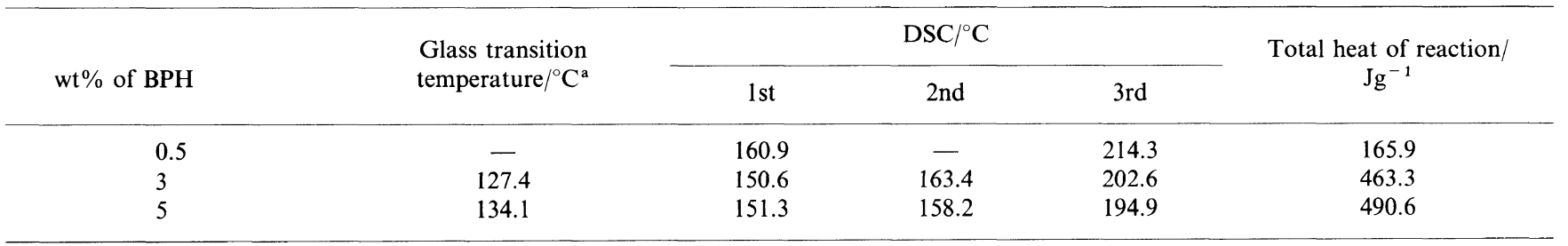

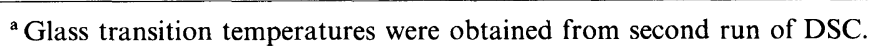
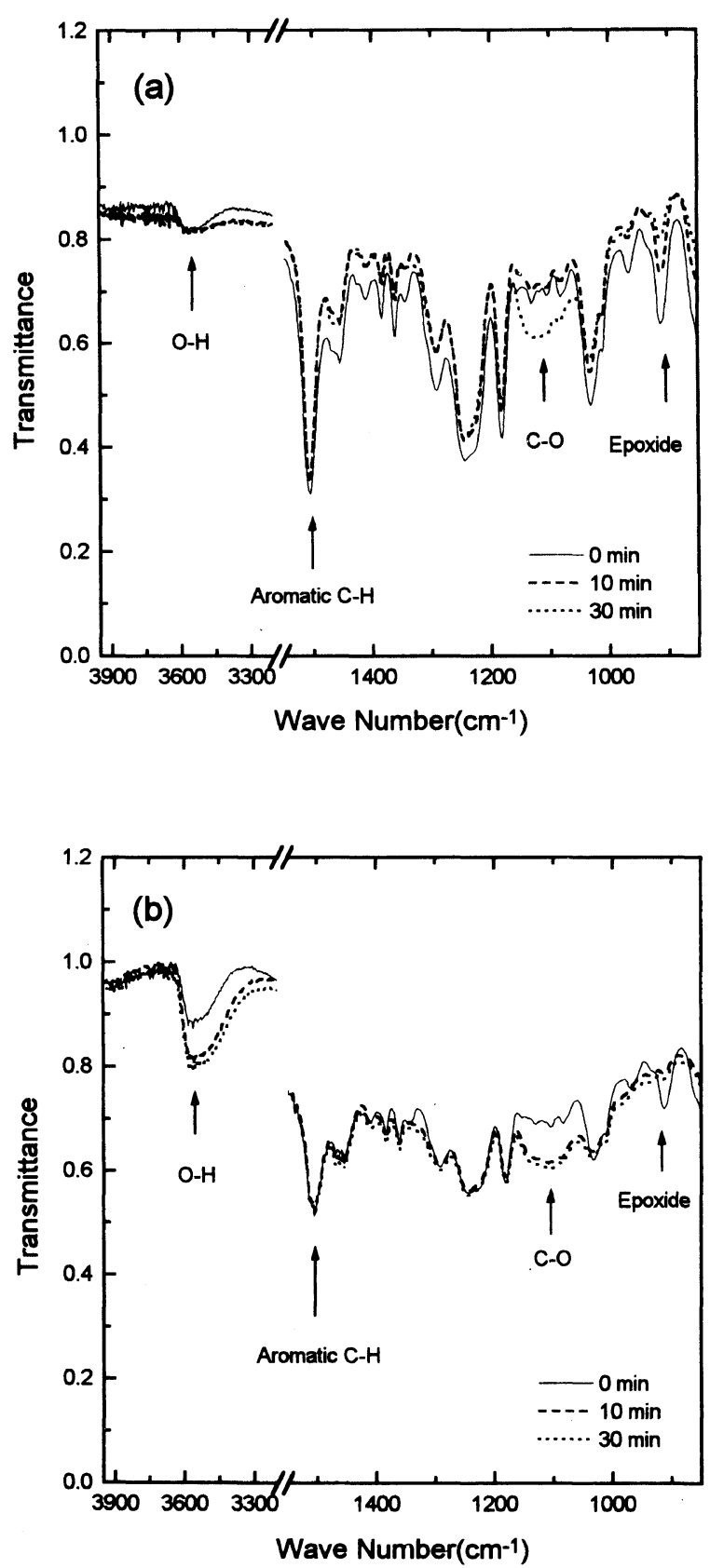

Figure 5. FT-IR spectra at $150^{\circ} \mathrm{C} v$ s. time during cure: (a) $0.5 \mathrm{wt} \%$; (b) $5.0 \mathrm{wt} \%$.

is high as shown in Figure 4. This result clarified the reaction mechanism for DGEBA/BPH system in this work. The thermal characteristics of DGEBA/BPH system are summarized in Table I.

Figure 5 shows the infrared spectra of DGEBA/BPH systems during the progress of curing at $150^{\circ} \mathrm{C}$. To discuss the results from FT-IR experiments, it is first

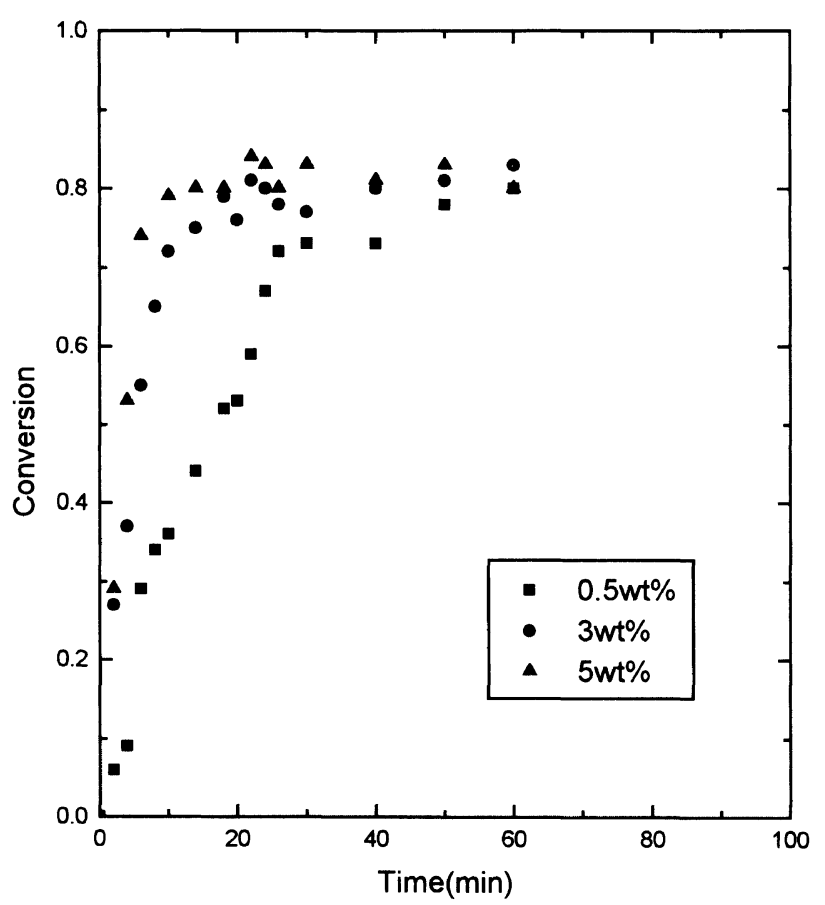

Figure 6. Conversion of epoxide vs. time at $150^{\circ} \mathrm{C}$.

necessary to assign the peak. There have been a large number of investigations using FT-IR for epoxy/amine systems. ${ }^{14-16}$ The most common reference band is the $\mathrm{C}-\mathrm{H}$ stretch associated with the aromatic hydrogens in the monomer chain backbone $\left(1510 \mathrm{~cm}^{-1}\right)$, since it is a very strong absorption and is not involved in any of the cure reaction. Ether bands are usually found between 1000 and $1200 \mathrm{~cm}^{-1}$. A hydroxyl absorption peak occurs at $3500 \mathrm{~cm}^{-1}$. Epoxide band occurs at $913 \mathrm{~cm}^{-1}$. In case of epoxide peak of $0.5 \mathrm{wt} \%$ sample, the peak intensity gradually decreases with increasing of curing time even though small peak remains for the cured sample during one hour due to the excess of epoxide. On the contrary, as increasing the concentration of BPH, the peak intensity of epoxide sharply decreases with increasing of curing time, and then the peak almost disappears. The $\mathrm{C}-\mathrm{O}$ peaks $\left(1100 \mathrm{~cm}^{-1}\right)$ increases with increasing of curing time for all formulations. This behavior reveals the production of $\mathrm{C}-\mathrm{O}$ peak by the propagation reaction of epoxide groups. This result may be considered that the addition reaction of epoxide goes on at the elevated temperature. Therefore, the degree of conversion of epoxy resin was measured from the disappearance of the peak at $913 \mathrm{~cm}^{-1}$. The formula used to calculate is;

$$
\alpha_{\mathrm{E}}(t)=1-\frac{\left(A_{913} / A_{1510}\right)_{t=t}}{\left(A_{913} / A_{1510}\right)_{t=0}}
$$



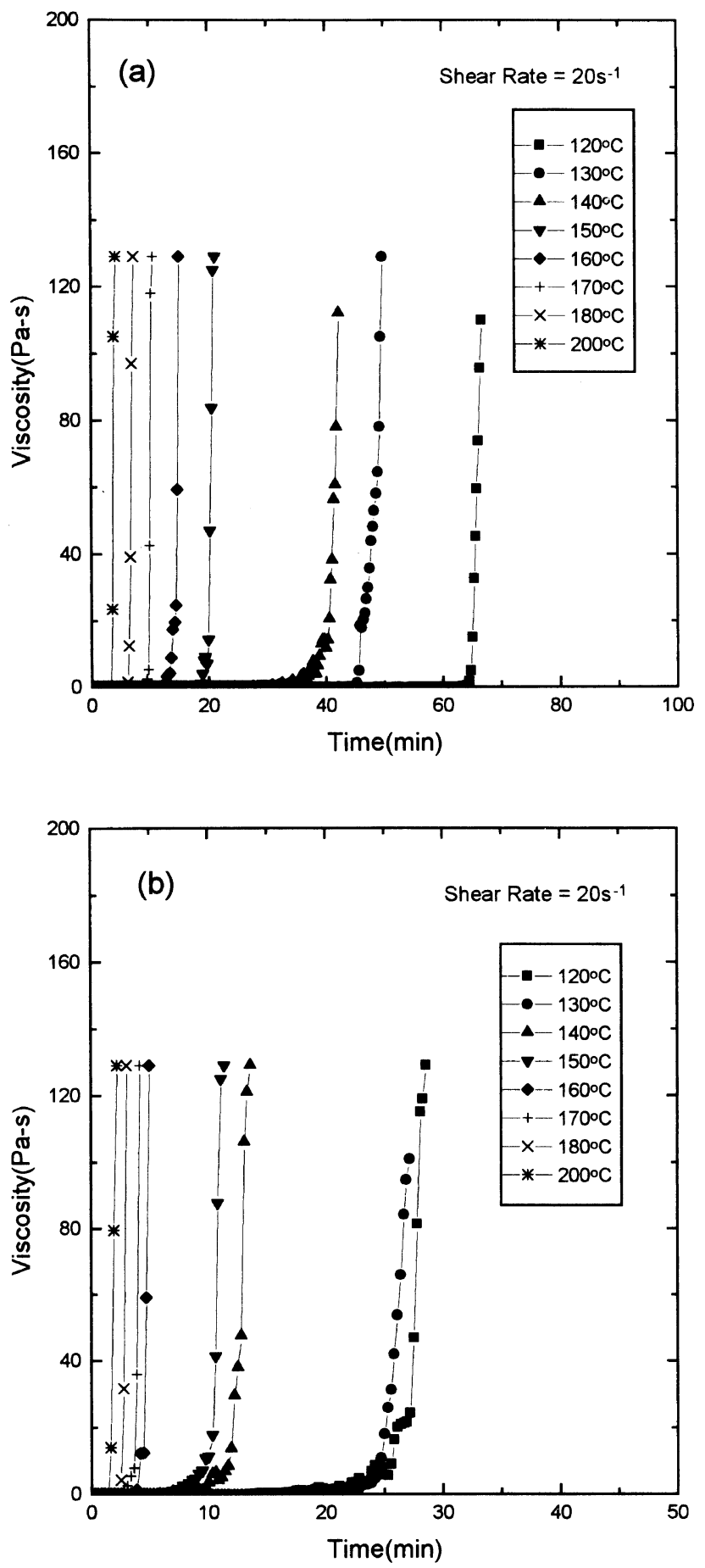

Table II. The characteristic of GGEBA/BPH system

\begin{tabular}{ccccc}
\hline wt\% of BPH & $\begin{array}{c}\text { Time } 1^{\mathrm{a}} / \\
\min \end{array}$ & $\begin{array}{c}\text { Time } 2^{\mathrm{b}} \\
\min \end{array}$ & $\begin{array}{c}E^{\mathrm{c}} / \\
\mathrm{kJ} \mathrm{mol}^{-1}\end{array}$ & $\begin{array}{c}\text { Correlation } \\
\text { factor }\end{array}$ \\
\hline 0.5 & 160.9 & - & 25.6 & 0.99876 \\
3 & 150.6 & 163.4 & 25.3 & 0.99635 \\
5 & 151.3 & 158.2 & 25.7 & 0.99862 \\
\hline
\end{tabular}

${ }^{\mathrm{a}}$ The time when the viscosity is $30 \mathrm{Pas}$ at $150^{\circ} \mathrm{C}$. ${ }^{\mathrm{b}}$ The time when the conversion of epoxide reaches constant value at $150^{\circ} \mathrm{C}$. ${ }^{\circ}$ Activation energy by Arrhenius plot in induction time.

where $A_{913}$ and $A_{1510}$ are the peak areas for epoxide and aromatic $\mathrm{C}-\mathrm{H}$, respectively.

Figure 6 shows the relationship between the conversion of epoxide group and curing time at three com-

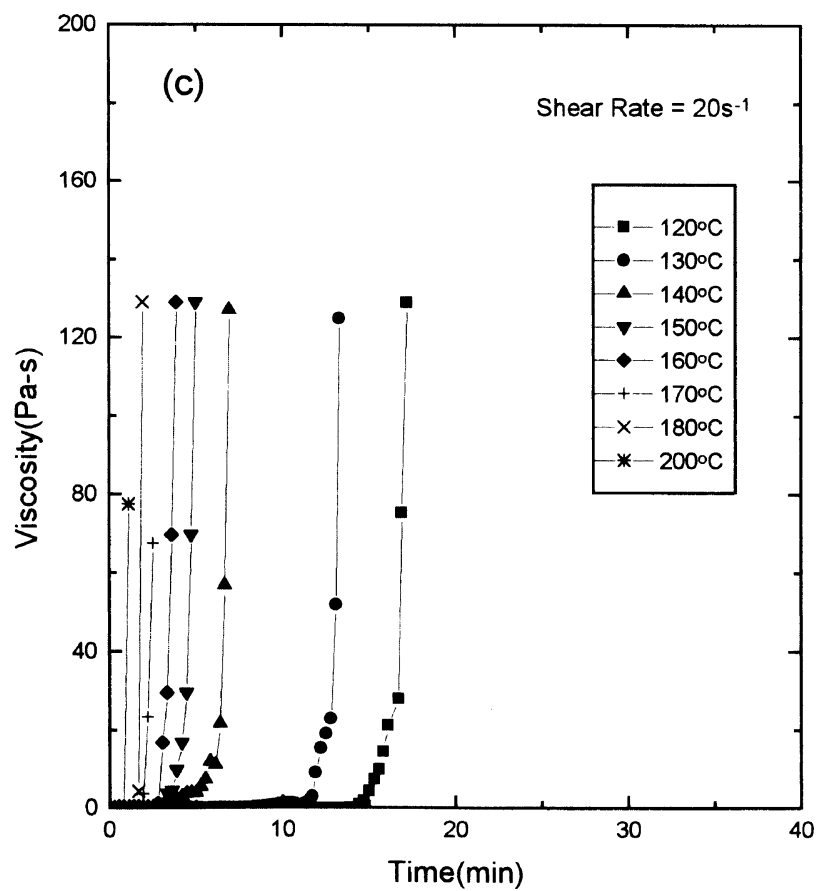

Figure 7. Viscosity profiles of various temperatures at constant shear rate: (a) $0.5 \mathrm{wt} \%$; (b) $3.0 \mathrm{wt} \%$; (c) $5.0 \mathrm{wt} \%$.

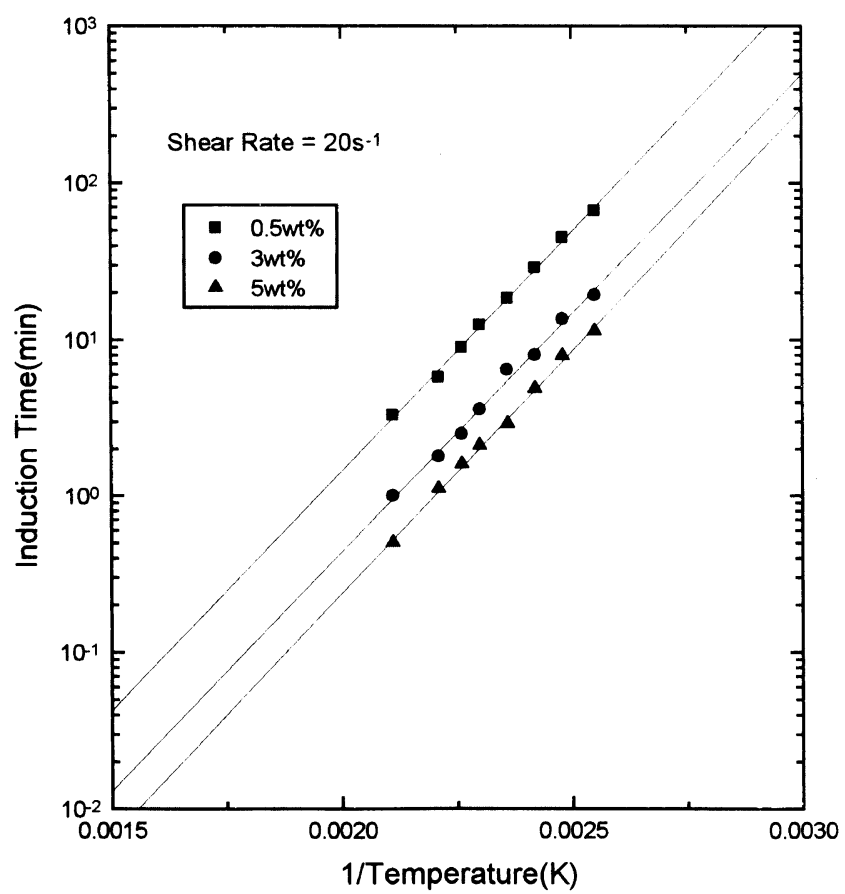

Figure 8. Arrhenius plot of induction times at constant shear rate

positions. The conversion of epoxide group gets to a plateau value for all formulations. The value is about $80 \%$. The conversion of $5 \mathrm{wt} \%$ sample reaches this value in short time compared to that of $0.5 \mathrm{wt} \%$ sample as shown in Table II. The spectroscopy of hydroxylcontaining compounds is frequently complicated by the occurrence of hydrogen bonding. For the $\mathrm{O}-\mathrm{H}$ peak of $5 \mathrm{wt} \%$ sample, the peak intensity of hydroxyl group increases with increasing of curing time. But the peak intensity of $0.5 \mathrm{wt} \%$ is nearly constant during the progress of curing. For the $5 \mathrm{wt} \%$ sample of $\mathrm{BPH}$, the fact that the $\mathrm{O}-\mathrm{H}$ peak intensity increases with the isothermal 


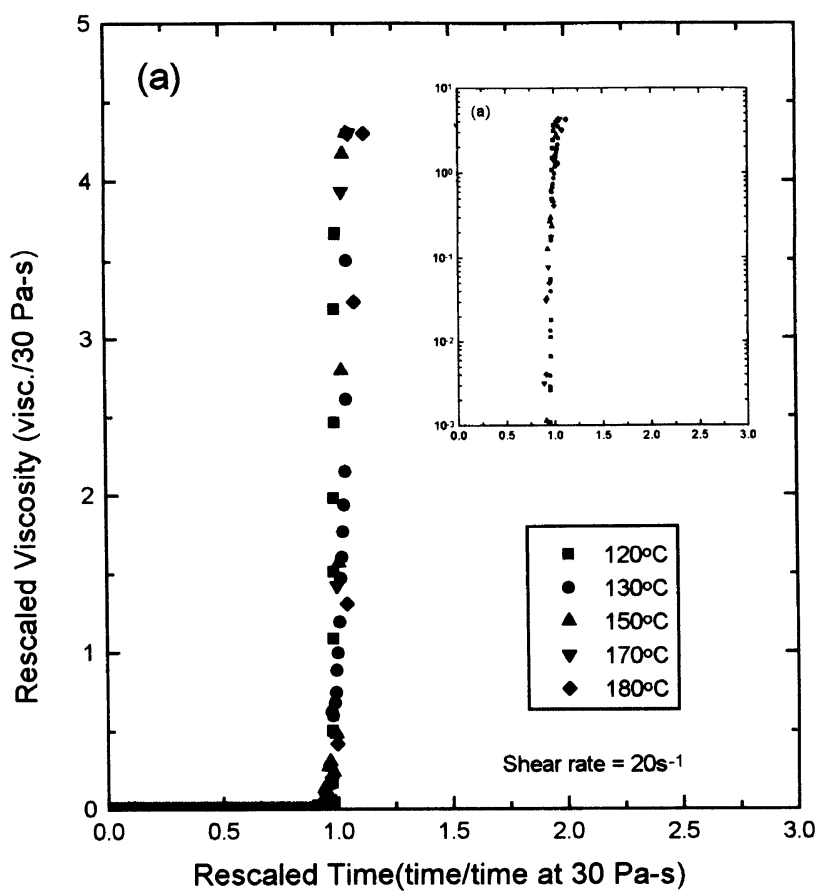

time, could explain that the curing process might lead to more network structure inducing changes in $\mathrm{O}-\mathrm{H}$ intramolecular hydrogen bonding at higher concentration of BPH. ${ }^{15}$

\section{Rheological Behavior in Steady Shear Measurements}

In order to analyze the influence of temperature on the viscosity, the steady shear viscosity at isothermal conditions was monitored by using the parallel plate geometry. Viscosity profiles obtained at 120, 130, 140, $150,160,170,180$, and $200^{\circ} \mathrm{C}$ are reported in Figure 7. In the initial stage of gelation, the molecular weight slowly increases as a consequence of the chain growth of the mixture with the time to be studied. As the polymerization goes on, there is a strong increase of viscosity of the system owing to the progressive formation of a tridimensional polymeric network. The parameter intended to be used for determining the gelation process in epoxy system is the induction time. This time may be obtained from the curve in Figure 7 from the intersection of the last trace of the linear fraction. Assuming that the reaction delay is governed by thermally activated processes, the induction times, $t_{i}$, can be described by the following Arrhenius expression ${ }^{10,17,18}$;

$$
t_{i}=K_{t} \exp \left(E_{t} / R T\right)
$$

where $E_{t}$, activation energy; $R$, ideal gas constant; $T$, temperature.

This assumption was confirmed by the linear behavior observed in Figure 8. The activation energies obtained for $0.5,3$, and $5 \mathrm{wt} \%$ are $25.6,25.3,25.7 \mathrm{~kJ} \mathrm{~mol}^{-1}$, respectively. The values of activation energy are approximately the same for all the epoxy/BPH systems studied, which indicates that the overall mechanisms are nearly same. The activation energies obtained in this system are lower values than the other system previously reported by that were $38 \mathrm{~kJ} \mathrm{~mol}^{-1}$ for DGEBA/DDM, ${ }^{7}$ $78 \mathrm{~kJ} \mathrm{~mol}^{-1}$ for the brominated epoxy/DICY, ${ }^{8}$ and 101 $\mathrm{kJ} \mathrm{mol}^{-1}$ for the cycloaliphatic epoxy-diphenyliodonium
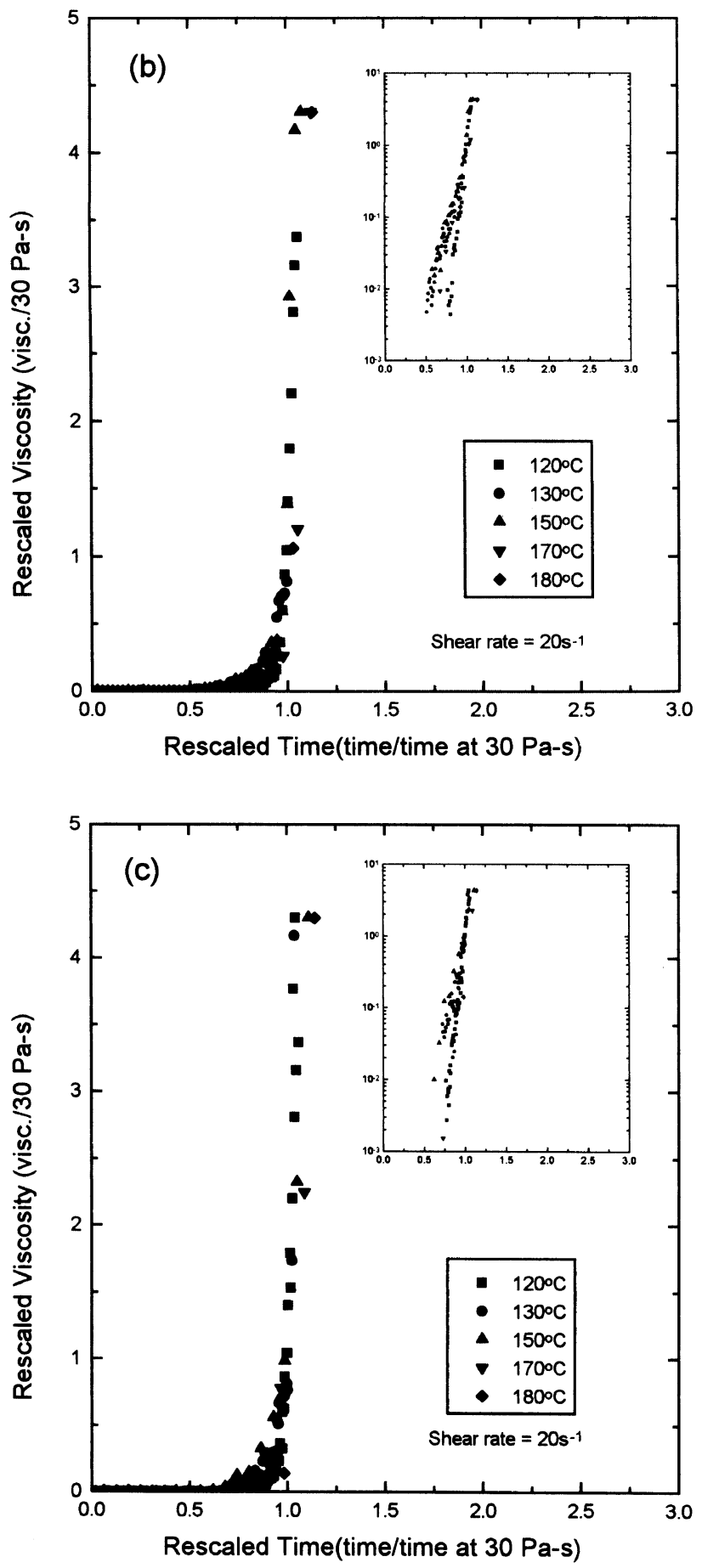

Figure 9. Generalized curve of viscosity $v s$. time at constant shear rate: (a) $0.5 \mathrm{wt} \%$; (b) $3.0 \mathrm{wt} \%$; (c) $5.0 \mathrm{wt} \%$.

hexafluoroarsenate. ${ }^{5}$ Another parameter also given in published work defining the gelation process consists of taking the value where viscosity reaches a certain value within dramatic increase in viscosity. As reference value, $30 \mathrm{~Pa}$ s has been taken for our system. Figure 9 shows a generalized curve for various temperatures, where viscosity is divided by $30 \mathrm{~Pa}$ s and time is divided by an arbitary time, $t_{30 \text { pas }}$. Although the curves give the small deviation at initial stage, a unique curve for all samples is obtained. That is, the curing mechanisms which may take place under the applied conditions seem to remain fixed for the interval of temperature studied. Table II represents the time when the viscosity reaches 


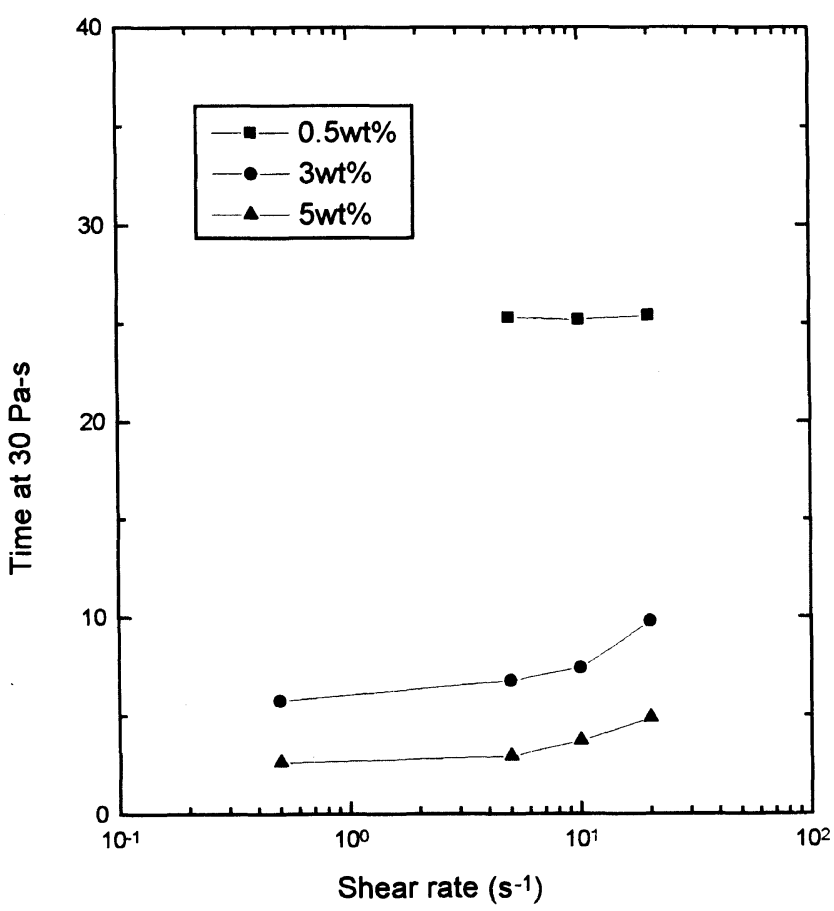

Figure 10. Shear rate dependence of induction time at $150^{\circ} \mathrm{C}$.

$30 \mathrm{Pas}$ and the conversion of epoxide group reaches $80 \%$ at $150^{\circ} \mathrm{C}$. The agreement between FT-IR results and viscosity data is satisfactory in this case. Comparing the generalized curves at the initial stage, the curve for $0.5 \mathrm{wt} \%$ shows a lower deviation than that for the higher concentration of BPH. In order to clarify the contribution of the BPH concentration to viscosity change, the logarithmic viscosity is plotted in Figure 9. The deviation of viscosity pattern at initial stage becomes apparent with increasing of the concentration of $\mathrm{BPH}$. It is recognized from this fact that the structural change for the higher concentration is larger than that for the $0.5 \mathrm{wt} \%$ in the initial stage. The shear rate dependence of the induction time is shown in Figure 10 for the isothermal cure of epoxy $/ \mathrm{BPH}$ systems at $150^{\circ} \mathrm{C}$. The induction times of $0.5 \mathrm{wt} \%$ of BPH showed the independence of shear rate within the test range. The other way, the induction times increased with shear rate for the higher concentration samples of BPH. The shear rate dependence on gelation time has earlier observed by Tung $e t$ $a l^{8}$ and Kenny et al. ${ }^{18}$ for epoxy gels, and is explained as analogous to the increase of glass transition temperature with increasing of shear rate. It seems reasonable to consider that the increasing of shear rate leads to a higher $T_{\mathrm{g}}$ which is resulted in a longer time to gel in an isothermal cure. Here, it may be considered that the increasing of induction time with the shear rate largely depends on the degree of structural change in gelation state. Therefore, for this cationic cure system, it can be interpreted that the dependence of temperature and shear rate for viscosity is related to the structural change based on the initiation reaction with increasing of BPH concentration.

\section{CONCLUSION}

The catalyst prepared in this work acts as thermally latent cationic initiator in the curing reaction of epoxy resin. Owing to the composition dependence of initiation reaction, the growing behavior of viscosity and the structural change such as linear growth and gelation depend on the BPH concentration. As observed with gelation process, the induction time is influenced by the process temperature and shear rate. From the Arrhenius type equation, the activation energies $\left(E_{t}\right)$ are in the range between 25 and $26 \mathrm{~kJ} \mathrm{~mol}^{-1}$. These results clearly show that the overall curing reaction is nearly same.

Acknowledgments. This work was supported by the Ministry of Science and Technology of Korea (KG9613). One of authors (J.R.L) thanks to Dr. S-B. Lee in KRICT of Korea for the valuable assistance with catalyst preparation and to Prof. J. A. Manson of Swiss Federal Institute of Lausanne for the fruitful discussion with thermal properties in this work.

\section{REFERENCES}

1. J. V. Crivello and J. L. Lee, Macromolecules, 14, 1141 (1981).

2. I. I. Abu-Abdoun and A. Ali, Eur. Polym. J., 29, 1439 (1993).

3. S. P. Pappas and L. H. Hill, J. Coat. Technol., 53, 43 (1981).

4. T. Endo, A. Kikkawa, H. Uno, and H. Sato, J. Polym. Sci., Polym. Lett. Ed., 27, 73 (1989).

5. J. Gu, S. C. Narang, and E. M. Pearce, J. Appl. Polym. Sci., 30, 2997 (1985).

6. K. Morio, H. Murase, and H. Tsuchiya, J. Appl. Polym. Sci., 32, 5727 (1986)

7. P. G. Babayevsky and J. K. Gillham, J. Appl. Polym. Sci., 17, 2067 (1973).

8. C. M. Tung and P. J. Dynes, J. Appl. Polym. Sci., 27, 569 (1982).

9. D. Adolf, J. E. Martin, and J. P. Wilcoxon, Macromolecules, 23, 527 (1990).

10. J. J. Imaz, N. Markaide, M. J. Jurado, M. A. Corcuera, and I. Mondragon, Eur. Polym. J., 28, 299 (1992).

11. P. J. Halley and M. E. Mackey, Polym. Eng. Sci., 36, 593 (1996).

12. S. B. Lee, Y. S. Park, K. W. Lee, and T. Endo, Chem. Lett., 17, 287 (1995).

13. H. F. Mark, R. M. Bikales, C. G. Overberger, G. Menges, and J. I. Kroschwitz, Encyclopedia of Polym. Sci. Eng., Second Ed., 6, 340 (1986).

14. Y. G. Lin, H. Sautereau, and J. P. Pascault, J. Polym. Sci., Polym. Chem. End., 24, 2171 (1986).

15. X. Wang and J. K. Gillham, J. Appl. Polym. Sci., 43, 2267 (1991).

16. T. P. Skourlis and R. L. Mccullough, J. Appl. Polym. Sci., 62, 481 (1996).

17. J. M. Kenny, A. Maffezzoli, and L. Nicolais, Compo's. Sci. \& Technol., 38, 339 (1990).

18. J. M. Kenny and M. Opalicki, Composite Part A, 27A, 229 (1996). 